\title{
İki Seyyah Bir Kültür: Broquière ve İbn Battûta Seyahatnâmelerine Göre Türklerde Yemek Kültürü
}

\author{
Dr. Öğr. Üyesi Mehmet Ali Kapar \\ Karamanoğlu Mehmetbey Üniversitesi, Edebiyat Fakültesi \\ Tarih Bölümü \\ mkapar78@gmail.com
}

Öz

Yemek ve içmek insan yaşamının devam edebilmesinin en temel ögesidir. Fakat insanlar sadece hayatlarını idame ettirmek için yemezler ve içmezler. Aynı zamanda yemek; bir sınıf göstergesi, milletler arasındaki ilişkilerde bir gösteri vesilesi, boş vakitlerde yapılacak bir faaliyet, şenlikler için bir vesile unsurudur. Yemek kültürü incelenerek toplumların tarihsel gelişimleri de izlemlenebilir. Türkler, köklü bir tarihe ve güçlü bir kültür birikimine sahiptirler. Sahip oldukları bu kültür birikiminin önemli bir parçası da yiyecek ve içecek alışkanlıkları ile bunun etrafında şekillenen kültürel unsurlardır. Türkler, genel olarak İslam öncesi Orta Asya bozkır hayatında şekillenen bu alışkanlıklarını göçlerle birlikte gittikleri coğrafyalara taşımışlar, yeni bölgelerdeki toplumları etkileyerek ve onlardan etkilenerek kültürlerini devam ettirmişlerdir. Ayrıca farklı inançlarla karşılaşmaları ve özellikle İslamiyet başta olmak üzere değişik dinlere tabi olmaları, yiyecek ve içecek alışkanlıklarının değişmesini de beraberinde getirmiştir. Yemek kültürünün izlerini günümüzde de görmek mümkündür. Seyyahlar, sadece üst yönetici sinıf ile görüşen olup onları yazan değil aynı zamanda toplumun alt sınıfları ile de muhatap olan ve bunları aktaran kişiler olması nedeniyle daha ayrıntılı bilgiler sunmaktadır. Çalışmamızda Orta Çağ'da Türklerin yaşadığı coğrafyaya seyahat eden seyyahların gözüyle Türklerdeki yemek kültürünü inceledik. Seyahatnâmelerinden istifade ettiğimiz seyyahları seçerken Bertrandon de la Broquière ve İbn Battûta gibi farklı bölgelerden ve dinlerden olanlarını tercih ettik. Ayrıca günümüze kadar gelen yeme içme kültürünü de tespit etmeye çalıştık. Bu araştırmada daha fazla seyahatnâmeye yer verilebilirdi fakat bir makale boyutunu aşacağ için iki seyyahın seyahatnâmesi ile sınırlı tuttuk.

Anahtar Kelimeler: Türk, yemek kültürü, seyahatnâme, Broquière, İbn Battûta.

\section{Two Travellers, One Culture: Food Culture in Turks according to the Travels of Broquière and Ibn Battûta}

\section{Abstract}

Food and drink are the most fundamental elements of human life. However, people simply don't eat and drink to survive. Food culture is a class indicator, a demonstration in relations between nations, an activity to be done in leisure time and an element of occasion for festivals. The historical development of societies can be monitored by following the food 
culture. Turks have a long history and a strong cultural background. An important part of this cultural accumulation they possess is the food and drink habits and the cultural elements shaped around it. The Turks moved these habits, which were shaped in the preIslamic Central Asian steppe life, to the territories where they migrated with migrations and continued their culture by influencing the societies in these new regions and by being influenced by them. In addition, they met with different beliefs and were subject to different religions, especially Islam. It is possible to see the traces of these habits today. Travellers can have more detailed information because they are not only concerned with the senior class but also sub-classes of the society and tell. In our study, we examined the food culture of Turks in the Middle Ages through the eyes of travellers traveling to the region where Turks live. While choosing travellers whose travel books we benefited from, in order to capture different points of view, we preferred those from different regions and religions such as Bertrandon de la Broquière and İbn Battûta. In this study, we have also tried to determine the culture of eating and drinking which has survived to the present day. We wanted to give more places for travel books in the study, but we limited it with travel books of the two travellers because it will exceed the size of an article.

Keywords: Turkish, food culture, travel book, Broquière, İbn Battûta. 


\section{GİRIŞ}

Arapça gezmek, gezi anlamındaki seyâhat (aslı siyâhat) kelimesi ile Farsça nâme (risâle, mektup) kelimelerinden oluşan seyâhat-nâme gezi mektubu, gezi eseri manalarına gelir. Fars Edebiyatı'nda ise karşıllı̆̆ sefer-nâmedir. Arap Edebiyatı'nda seyahat ve seyahatnâme anlamında daha çok rihle kelimesi kullanılır. Rihle, bir yerden bir yere göç etmek manasındaki rahl (veya aynı anlamdaki irtihâl) mastarından isim olup göç demektir. Eski Arap şiirinde, Kur'an'da ve Hadislerde rihle gö̧̈, yolculuk, gezi, seyahat anlamlarında kullanılmış, Kur'an'da, Kureyş kabilesinin ticaret amacıyla yaptığı yolculuk ve seyahatler içinde yine rihle kelimesi kullanılmıştır (Yazıcı, 2007, s. 9).

İçerisinde var olduğu toplum ve kültürün dışında başka dünyaların, yaşantıların da var olduğu bilgisi, insanlarda o farklı medeniyetleri tanıma duygusunu doğurur. Ayrıca insanoğlu kendisine yeni yaşam yerleri bulma, keşfetme, ticaret, siyasi amaçlar, ajanlık, elçilik gibi nedenlerle de seyahat eder. Seyahatnâmeler ise çeşitli amaçlarla yapılan bu seyahatler dolayısıyla kaleme alınan eserlerdir. Seyyahlar gezip gördükleri yerleri kendi gözlerinden eserlerinde yansitırlar ve bu eserlerden; tarih, coğrafya, jeoloji, sanat, edebiyat, etnoloji, antropoloji gibi pek çok alan üzerine bilgi toplamak mümkündür. Seyahatnâmeler dışarıdan bakan ve dolayısıyla farklı perspektife sahip özelliğiyle daha sıra dışı bir değerlendirme yapmayı mümkün kılmaktadır.

Yemek yeme ve beslenme, kültürün bir parçası olması hasebiyle topluluklara göre farklılıklar gösterir. Bu farklılıklar iklime, coğrafi yapıya, tarım veya hayvancılığa dayalı ekonomik yapıya ve en önemlisi geleneklere göre şekillenir ve bu süreçte beslenmeye dair belirli alışkanlıklar kazanılır. Bu nedenle toplumların kültürlerinde önemli bir yere sahip olan yemek, Türk kültürünü de şekillendiren dikkat çekici bir unsur olarak karşımıza çıkmaktadır. Türkler, tarihî süreç içerisinde gerek yaşadıkları coğrafî unsurların, gerekse siyasi olayların bir sonucu olarak birçok bölgeye göç etmiş̧ir. Bu göçlerle birlikte yine birçok kültürle tanışan Türkler, bunları etkilediği gibi, aynı zamanda bunlardan etkilenmiş ancak yine de kendi kültürünün çoğu özelliğini korumayı başarmıştır.

Seyahatnâmeler sadece siyasi olayları anlatmayıp toplum yaşamını en güzel yansıtan kaynaklardandır. Bu yönü ile yemek kültürü de dâhil olmak üzere toplumsal değişimleri ve korunmuş kültürel unsurları da takip edebilmemizi sağlamaktadır. Çeşitli kültürlerden gelen seyyahlar kendi kültürleri çerçevesinde olayları değerlendirdikleri için eserlerinde daha farklı bilgiler bulmak mümkündür. Bu nedenle biz bu çalışmamızda bir doğulu, bir de batılı seyyahı seçerek Orta Çağ Türk dünyasındaki yemek kültürüne bakmaya çalışacağız. İnceleyeceğimiz seyyahlar ise Fas kökenli bir Müslüman olan İbn Battûta ile Fransız kökenli bir Hristiyan olan Bertrandon de la Broquière 'dir.

\section{İbn Battûta'nın Seyahatnâmesi}

Orta Çă̆'ın en büyük seyyahlarından olan seyahatnamenin yazarı İbn Battûta'nın tam adı Ebu Abdullah Muhammed b. Abdullah b. Muhammed b. İbrahim Levâtî Tancî'dir. Literatürde Rıhletü İbn Battûta olarak bilinmesine rağmen bizzat müellifin kendisi tarafından verilen eserinin ismi ise Tuhfetü'n-nüzzâr fi gara'ibi'l-emsâr ve acấ'ibi'l-esfâr'dır. 14. yüzyıl gezginlerinden olan İbn Battûta 17 Recep 703/25 Şubat 1304 yılında Fas'ın Tanca şehrinde dünyaya geldi. Bu şehirden çıktığı günden itibaren 28 yıl süren gezileri boyunca Mısır, Arap Yarımadası, Irak, İran, Anadolu (başta Osmanlı Beyliği olmak üzere o dönemin belli başlı beylikleri), Deşt-i Kıpçak, Bizans (İstanbul), Orta Asya, Hindistan, Maldivler, Çin ve 
Endülüs'ü gezdi. İbn Battûta kaleme aldığı eserinde, gördüğü ülke ve şehirlerin 700 yıl önceki durumlarını başarıyla yansıtır. Gittiği yerlerin devlet ve toplum yapılarını, inanç ve âdetlerini, doğal özelliklerini ve ürünlerini tanitır. İbn Battûta 770/1368'de TamesnaMerrakeş kadısı iken vefat etti (İbn Battûta, 2000, s. I/XXIV-XXXV). İbn Battûta'nın Seyahatnâmesinden anlaşıldığına göre o henüz 22 yaşında iken 2 Recep 725/14 Haziran 1325 'te Tanca'dan hac niyetiyle yola çıtı. Seyahatnâmede Mısır Memlûklarından bahsederken doğrudan Etrâk (Türkler) kelimesini kullanması ve ileride görüleceği üzere Memlûk egemenlik alanını da aynı Anadolu gibi "Türk ülkesi" tabiriyle anması dikkat çekicidir. O dönemin önemli simalarından İbn Haldun da kitabında Mısır Memlûk Devleti için "Devletü't-Türk" ifadesini kullanır (İbn Battûta, 2000, s. I/XXIV-XXXV; İbn Haldûn, 1956, s. 564-566).

Türklerin, Moğolların, Maldivlilerin hükümdarlarıyla tanışan İbn Battûta derviş gibi giyinmesi ve dervişçe davranması sebebiyle, halk ve ulema tarafından sevilmiştir. İbn Battûta, Marco Polo ile birlikte Orta Çağ'ın en büyük iki seyyahından biridir ve hatta çok daha geniş bir alanı gezmesi, üç kıtada en önemli kültür merkezlerine ulaşması sebebiyle onu geride bırakmıştır. Ayrıca İbn Battûta gezdiği birçok ülkede sosyal hayata karışmış, evlilikler yapmış ve hatıralarını güvenilir birine yazdırmıştır. Ayrıntıları asla ihmal etmeyen İbn Battûta, eserinde insan unsuruna en fazla yer veren seyyahtır. Çeşitli milletlerin giyim kuşamı, âdetleri ve inançları hususunda ayrıntılara inmiştir. Avrupa hariç neredeyse Eski Dünya'nın tamamını gezen İbn Battûta'nın verdiği bilgiler, Türklerin ve Moğolların tarihi açısından çok önemlidir. Er-Rihle'de Anadolu'nun o günkü durumu hakkında ayrıntılı bilgi vardır. Eser; beyliklerin iç ihtilafları, Umur Bey'e karşı düzenlenen Haçlı saldırısı, Alanya'nın milletlerarası bir liman oluşu, Germiyanoğullarına karşı duyulan güvensizlik, Eretna Devleti'nin refah seviyesi, Sinop'un stratejik değeri, Erzurum ve Erzincan'da birbirleriyle çarpışan Türkmen kabileleri, Anadolu genelinde Hanefi mezhebinin yaygın oluşu, İlhanlıların Anadolu siyaseti, Çobanoğulları, Ahiliğin yükselişi vb. hakkında bilgi veren o dönemin en önemli çağdaş kaynaklardandır. Bu eser sosyal hayat, âdetler, inançlar ve töreler hakkında çok zengin malzeme ihtiva etmektedir. Nitekim burada yemek tariflerinden bayram ve matem giysilerine, siyasetten tasavvufa kadar o dönemin insanıyla ilgili her konuda bilgi verilmiştir (Aykut, 1999, s. 361).

\section{Bertrandon de La Broquière Seyahatnâmesi}

Bertrandon de la Broquière, Fransa'da Toulouse yakınındaki la Broquière arazisinin sahibi olan bir soyludur ancak soy kütüğü tam olarak bilinmemektedir. 1421'de Burgonya Dukası III. Philippe le Bon'un sarayında "écuyer tranchant" (hükümdarın sofrasında hizmet eden bir soylu) olarak tarih sahnesine çıkmıştır. Philippe le Bon'un çok güvendiği bir kişi olan Bertrandon 1432'de Yakın Doğu'ya gizli bir seyahat yapmakla görevlendirilmiş ve kendisinden İslam devletleriyle gittikçe güçlenmekte olan Osmanlılar hakkında bilgi getirmesi istenmiştir (Eyice, 1992, s. 524).

1432 yılında Fransa'nın güneyine inmek üzere yola çıkan Broquière, Bologna-Floransa yoluyla Roma üzerinden Venedik'e gelmiş ve buradan bir gemi ile Akdeniz'e açlarak Yafa'ya çıkmıştır. Bu, aynı zamanda İslam topraklarına ilk ayak basışıdır. Kudüs ve çevresindeki kutsal yerleri Hristiyan bir hacı görünümü altında gezen Broquière, bundan sonraki bölümleri diplomatik bir çerçevede yürütmüştür. Suriye üzerinden Anadolu'ya giriş yapmış ve Anadolu'yu boydan boya gezmiş, nihayetinde Osmanlı Devleti topraklarından geçerek Bizans İstanbul'una girmiştir. Burada bir süre dinlendikten sonra Edirne, Filibe, 
Belgrad ve Viyana'ya uğramış, ardından da Fransa'ya, memleketine dönmüştür. Bertrandon'un hacı görünümü altında bir gizli ajan olarak yaptı̆̆ı ve o çağda son derecede güç olan bu uzun seyahatin esas gayesi, Türklerin politik durumlarını yerinde incelemek ve Philippe le Bon'un tasarladığı yeni bir Haçlı Seferi için zemin yoklamaktı. Bu görevi yerine getirirken Türkleri küçümseme yolunu tutmamış ve gerçek meziyetlerini, üstünlüklerini tanıtmaktan çekinmemiştir. Türk toplumunda gördüğü iyi şeyleri takdirle belirtmiş ve bu arada onları Hristiyanlardan mesela Rumlardan, Macarlardan üstün tuttuğunu da vurgulamaktan kaçınmamıştır (Eyice, 1975, s. 87).

\section{Sofra Kültürü}

Broquière, kervan ile yola çıtıktan sonra Türklerin yaşamlarını dikkatli bir şekilde gözlemlemiş ve kısa sürede uyum sağlamıştır. Bu esnada Sultan'ın memlüklerinden olan ve Karaman'daki bir kardeşini ziyarete giden, adını ise ilerleyen sayfalarda Mehmet olarak vereceği bir Çerkez ile arkadaş olur. Bu kişi ile samimiyeti geliştirir ve birbirlerine yoldaşlık ederler. Çerkez Mehmet'in çadırı olmadığı için bazen bahçelerde bazen de ağaç altlarında gecelerler. Broquière toprak üzerinde yatmayı, şarap yerine su içmeyi, çok zor gelse de yere bağdaş kurup oturmayı burada öğrendiğini belirtir. Arkadaşı ile birlikte sofraya oturduğu ilk akşam peynir ekmek yerler ve süt içerler. Seyyahın dikkatini Türklerin kullanmış olduğu ve günümüzde sofra bezi olarak tabir ettiğimiz yemek örtüsü dikkatini çeker. Zira kendi sözlerinden o dönem Avrupası'nda kullanılmadığını anladığımız bu sofra bezini, sadece yüksek düzeydeki insanların kullandığını düşünür. Arkadaşı Çerkez Mehmet'in de bu örtüyü kullandığını, yemeğin bitiminde bu örtünün kapattığını anlatır. Durumu takdir edişini ise şu şekilde aktarır: "Böylece üstünde ne varsa, ne ekmek ne üzüm hiçbir şey ziyan olmuyor, hepsi içinde kalıyordu. Yeniden yemek yeneceği zaman, kaldırıldı̆̆ı gibi tekrar seriliyordu. Hiçbir zaman bir Türkün az da yese çok da yese yüksek sesle Tanrı'ya şükretmeden sofradan kalktığını görmedim" diyerek hayretini ifade eder (Broquière, 2000, s. 154-155).

İbn Battûta da Türklerin genelde yerde oturarak yemek yediklerini Seyahatnâmesinde ifade eder. Bu durumun bey olsun sıradan halk olsun böyle olduğunu ve değişmediğini söyler. Eğer resmî bir protokol yemeği ise buna uygun olarak oturulması gerekmektedir. İbn Battûta, Ramazan ayında Eğridir'e geldiğinde şehrin beyi olan Hamîdoğulları beyliğinin hükümdarlarından Dündar Bek oğlu Ebu İshak Bek tarafından misafir edilir. Seyyah, Eğridir' de Hızır Bey Camii'nin karşısındaki Dündar Bey Medresesi'nde kalmış, Ramazan ayı boyunca burada misafir edilmiştir (Kofuoğlu, 1997, s. 473). Bey, Ramazan gecelerinde üzerinde minder veya döşek bulunmayan bir kilime oturmakta ve büyücek bir yastığa yaslanmaktadır. Bey'in yanında dönemin fıkıh bilgini, onun yanına da İbn Battûta oturtulur. Biraz ötelerinde ise beyliğin ileri gelen memur ve kumandanları oturmaktadır. Onlar, bu oturma düzeninde iken yani protokolün yerini almasında sonra yemekler getirilir ve küçük tabaklarda servis edilir (İbn Battûta, 2000, s. I/407). Yine İbn Battûta, Lârende/Karaman'a geldiğinde Karamanoğlu Bedreddin Bey tarafından misafir edilir.1 Bedreddin Bey, misafirlerin en iyi şekilde ağırlanması için emirler yağdırmıştır. İbn Battûta'nın anlattığına göre burada kendisine gümüş tabaklar içerisinde leziz yemekler, nefis meyveler ve hoş tatlılar ikram edilmiştir. Ayrıca burada kendisine mum, elbise, binek hayvanı ve çeşitli armağanlar da verilmiştir (İbn Battûta, 2000, s. I/414).

135 (1334-35) yılında hükümdar olarak Lârende'de hüküm süren Bedreddin İbrahim Bey'den itibaren Karamanlı Beyliği'nin başşehri Lârende olmuş ve İbrâhim Bey burada bir saray yaptırmıştır (Sümer, 2001, s. 456).

SEFAD, 2019; (41): 427-444 
Broquière, Türklerle ilgili olarak izlenimlerini aktarırken zaman içerisinde onlara yakınlık duymaya başladığını da itiraf eder. Türklerle ilgili betimleme yaparken onların neşeli, şen şakrak insanlar olup canları isteyince türkü söylediklerini, türkülerin hayatlarının bir parçasını oluşturduğunu, hüzün ve düşüncenin ne olduğunu bilmediklerini yazar. Ayrıca her şeyi iyilikle karşıladıkları, sade ve zorlu bir yaşamları olduğunu belirtir. Ardından onların yemek kültürleri ile ilgili olarak "Yemek yerken çoğu zaman görmüşümdür, yanlarından bir fakir geçiyorsa onu kendileriyle birlikte yemek yemeğe çağırıyorlardl; bu bizim hiç yapmadığımız bir şeydi" şeklinde bir itirafta da bulunur (Broquière, 2000, s. 265).

\section{Törenlerde Yemek Kültürü}

İbn Battûta Kastamonu'ya vardığında Candaroğullarından Süleyman Bey ile tanışır. Hükümdar ile sohbetin ayrıntılarını anlattıktan sonra burada bir törenden bahseder. Buna göre ikindi vakti meclis kurulur, vakit geldikten sonra sofralar hazırlanır, kapılar açılır; yolcu, köylü, şehirli ve yabancı kim varsa gelir, kimse geri çevrilmez, herkese bir şeyler ikram edilir.

Özel divan ise sabahleyin erkenden kurulur. Burada önce Bey'in oğlu huzura gelir. Babasının elini öptükten sonra kendi dairesine gider. Onun ardından devletin üst düzey görevlileri huzura çıkarlar ve yemek yedikten sonra ayrılırlar (İbn Battûta, 2000, s. I/440).

İbn Battûta, Sinop'ta kaldıklarının on dördüncü gününde şehrin beyi İbrahim Bey'in annesinin vefat ettiğini ifade etmektedir. Cenaze merasimini anlatan İbn Battûta, tutulan yasın kırk gün sürdüğünü ve bu süre içinde her gün sofralar kurulup ziyafetler verildiğini söylemektedir (İbn Battûta, 2000, s. I/440). Bu olay aklımıza eski Türklerden kalma yuğ merasimini hatırlatmaktadır. Türkçe'de yas âdeti içinde değerlendirilen cenaze törenine "yuğ" ve bu törende söylenen sözlere "ağ $1 t$ " denilmektedir. Eski Türklerde yuğ töreninde cenazeye katılanlara yemekler verilir, ziyafet ne kadar büyük olursa ölüyü o kadar memnun edeceği düşünülürdü. İslamî dönemde ise bunun yerine ölünün ailesi değil, akraba ve komşuları yemek verir hâle gelmiştir. Ayrıca ölüm hâlinde yemek verme âdeti "ölü aşı" adı altında bugün dahi bazı Türk topluluklarında yaşamaya devam etmektedir (Hacıgökmen, 2013, s. 395-396).

İbn Battûta, Sinop'ta kırk gün kadar kaldıktan sonra deniz yoluyla Kırım'a geçer. Bundan sonra buranın beyi ile birlikte Üzbek Han'ın başkenti Saray şehrine beraber seyahate çıkarlar. Bu kısımda Türklerdeki yemek kültürü için özel bir bölüm açıp anlatan seyyah kıymetli bilgiler vermektedir:

"Türkler ekmek ve katı yiyecek yemezler; dûkî adın verdikleri, bizim anlîye benzeyen bir yemek yaparlar. Önce suyu ateşin üzerine koyarlar. Kaynayınca dûkîden bir parça içine atarlar. Yanlarnnda et varsa onu lime lime edip tencereye koyarlar ve beraber pişirirler. Yemek pişince herkesin payın tabaklara koyup servis yaparlar. Ve nihayet tabaklardaki yemeğin üzerine yoğurt dökerler. Yemekten sonra kısrak sütünden yapılan ve kımız adı verilen nesneyi içerler.

Türkler iyi karakterli, kuvvetli ve cesur insanlardır. Bazı vakitlerde burhani denilen hamur işini yerler. Bu yemek, küçük küçük kesilmiş hamur parçalardır aslında. Bunlar, ortalarnndan birer delik açlarak tencereye oturtulur. Pişirildikten sonra üzerine yoğurt dökülüp içilir. Ayrıca bir çeşit şıraları daha var ki demin bahsettĭğimiz dûkî tanelerinden yapiliyor. 
Tatlı yemek, onlar nezdinde ayıp karşılanır! Ramazan ayı içinde Sultan Uzbek'in huzurunda bulunuyordum. Sik sik yenmekte olan kısrak ve koyun eti vardı sofrada. Ayrıca "rişta" [=erişte] denilen ve şehriyeye benzeyen; piştikten sonra sütle karıştırılarak bir çorba da hazırlanmıştı.

O gece arkadaşlarımın yaptıkları tatlıdan bir tabak sundum sultana. Sultan sadece parmağıyla dokunup tatmakla yetindi, bir daha elini sürmedi! Tülük Tümûr'un anlattığına göre sultan bir gün çocuk ve torunlarının sayısı kırkı bulan saygın bir kapıkuluna şöyle demiş:

"Bu tatlyı yersen cümlenizi azat ederim!"

Ama adam şu cevabı vermiş:

"Beni öldürsen de yemem!" (İbn Battûta, 2000, s. I/466-467).

Burada bahsedilen dûkî (=düğ), Anadolu ağızlarında hâlâ yaşayan bir kelime olup, "dövülüp inceltilmiş" manasına gelmektedir. Nitekim döğü, Samsun-Çarşamba civarında" değirmende çekilerek yani dövülerek kırılmış, un ufak edilmiş mısır" anlamında kullanılmaktadır. Tokat, Amasya, Sivas, Niğde ve Karaman'da ise "düğ̈̈" ve "düğ" şeklinde "elendikten sonra geriye kalan ince bulgur" olarak bilinmektedir (İbn Battûta, 2000, s. I/489).

Burada geçen kımız, bir tür süt ürünü, önemli bir sofra tadı ve şifa kaynağı olup sadece kısrak sütünden yapılabilmektedir (Alptekin, 1992, s. 23). Türklerin at sütünden ürettikleri kımız içkisi Türklere özgü bir içecek olup günümüze kadar kullanılagelmiştir. Kısrak sütünden yapılan kımız, gerçekten de Hunlardan beri bilinmekte ve bazı dönemlerde, inek, deve ve eşek sütünden yapıldığı da ifade edilmektedir (Öcal, 1985, s. 202). Kımız besleyici niteliğinin yanı sıra az miktarda alkolü bünyesinde barındırmakta ve bu yönüyle rahatlatıcı bir özelliğe sahiptir. Ayrıca açlık giderici ve yüksek kalorili olup birçok hastalığın tedavi edilmesinde de kullanılmıştır (Rasonyi, 1971, s. 49). Kımızın "Uvız Kımız, Sarı Kımız, Tünemel Kımız, Karabalı Kımız, Sirge Kımız Cmyar Kımız" gibi türleri olduğu gibi, yirmi beş ayrı türünün varlığı da kaynaklarda geçmektedir (Üstün, 2009, s. 248). Burhani de, Farsça kebap anlamında "büryan" kelimesinin farklı bir söylenişi olabilir (İbn Battûta, 2000, s. I/489). Fakat Büryan Kebabı'nın menşeinin kime ait olduğu tam tespit edilememiştir (Ögel, 1978, s. 331). Büryan Kebabı'nın kelime yapısı itibariyle İran kültürüne yakın olduğu görülse de Moğol belgelerinde bu yemeğin Türklerden alınıp orijinal bir biçimde uygulandığına rastlanmaktadır (Öztürk, 2018, s. 121).

İbn Battûta Azak şehrindeki izlenimlerini anlatırken buradaki zaviyede, gelen giden yolculara yemek ikramlarında bulunulduğunun altını çizer. Burada kendisinin de iyi karşılandığını ve ziyafet tertip edildiğini anlatır. Bu bölgede konakladıkları esnada bölgenin beyi Tülük Tümûr da oraya gelmiştir. Tülük Tümûr hasta olmasına rağmen Özbek Han'1 görmek için başşehir Yeni Saray'a gitme hazırlığına girişmiştir. Böylelikle İbn Battûta içinde Volga seyahati başlar. Bu seyahatte Tülük Tümûr'a kardeşi, iki oğlu, hepsinin eşleri ve şehrin ileri gelenlerinden hocası Sadeddin, Hatib Ebû Bekir, Kadı Şemseddin, Fakih Şerefüddin Musa ve teşrifatçısı Alâeddin refakat eder (Koçyiğit, 2009, s. 6). Tülük Tümûr'un onuruna verilen yemek sırasında oğluyla kardeşi ve çocukları hizmette bulunmak için ayakta kalmışlardır. Daha sonra at eti ve diğer etlerden yapılmış yemekler getirilir, kısrak sütü ve boza sunulur. Yemek bitince güzel sesle okunan Kur'an dinlenir (İbn Battûta, 2000, s. $\mathrm{I} / 469)$.

SEFAD, 2019; (41): 427-444 
İbn Battûta'nın Kırım'a seyahat ettiği dönemde Kırım, Özbek Hanlığı'na (Altınordu Devleti) bağlı idi ve buranın yöneticisi Muhammed Özbek Han'ın komutanı Tülük Tümûr idi (Koçyiğit, 2009, s. 66). İbn Battûta, Sibirya bölgesindeki anılarını anlatırken Türklerin merasimleri hakkında ve bu merasimlerdeki yemek törenleri hakkında da kıymetli bilgiler verir. Burada bayram günlerine tekabül eden günlerde bulunur, otağda yapılan bayramlaşmaya ve törenlere de katılır. Tören şu şekilde gerçekleşir:

"Protokole göre herkes yerini aldıktan sonra altın ve gümüş sofralar üzerinde yemekler sunulur. Her sofrayı dört veya dörtten fazla kişi taşır. Her emirin önüne bir sofra getirilir. İpekli elbiseler giyen, ipekli bir önlük takan, belindeki kında koca bıçaklar ve satırlar taşıyan 'Bârûcîl parçalayıcı' gelir. Bârûcî, et parçalayan demektir. Her emirin bir bârûcîsı vardır. Sofralar kurulunca evvela onlar hücum ederek efendileri önünde yerlerini alırlar; arkalarında tuzlu su ile dolu altın yahut gümüşten mamul minik kaplar getirilir...

Onların ardından yine altın ve gümüş kaplarda içecekler getirilir. Meşrubatın büyük bir kısmını ballı şıralar oluşturuyor. Hanefi mezhebinde olduklarından dolayı nebizi helal sayıyorlar. Sultan şıra içmek isteyince kızı ayağa kalkar, kadehi alır, dizini yere koyup babasına sunar nazikçe; babası içtikten sonra kız ikinci bir kadeh alarak büyük hatuna sunar. Büyük hatun içtikten sonra diğere hatunlara sırayla uzatır. Onların ardından veliaht kadehi alır ve babasına sunar; aynı şekilde o da içtikten sonra hatunlara ve kız kardeşine sunar. Hepsinin önünde reveransla yapar bu işi. Onun ardından ikinci oğul kalkar, kadehi alır, kardeşine sunar. Onların ardından büyük beyler kalkar. Her biri veliahda sakilik ederler.

Nihayet bey çocukları kalkar, bu ikinci oğula kadeh sunarlar, önünde eğilirler. Bu arada şarkı söylemektedirler. Ben mescidin avlusunda kadı, hatip, şeyh ve fakihler için kurulan çadırda bulunuyordum. Bize de her birini Türklerin ileri gelenlerinden dört beyin taşıdığı altın ve gümüş kaplamalı sofralar çıkarıldı. Bugün huzurda sadece nüfuzlu beyler hizmetkârlı yaptığından hükümdar kim ne arzu ediyorsa bu beylere emrediyordu, hizmeti görülsün diye. Şeyhlerin bir kısmı altın ve gümüşsofralardan yemek yedi. Bir kısmı ise bunları kullanmaktan sakınarak yemek yemedi.

Sağımda ve solumda kımız tulumlarıyla dolu göz alabildiğine uzanan arabalar gördüm. Hükümdar yemek sonunda bu içkilerin orada bulunanlara dă̆ıtılmasımı emretti. Bundan bana tam bir araba düştü ama komşum olan Türklere hediye ettim! ..." (İbn Battûta, 2000, s. I/483-485).

İbn Battûta, Huvârezm "Harezm" Beyi Kutlû Dümûr'un memleketine geldiklerinde altın ve gümüş tabaklarda, altın kaşıklar eşliğinde tanelere ayrılmış nar, Irak yapımı porselen tabaklarda üzüm ve nefis kavunlar sunulduğunu söyler. Tabakların kenarlarında ise tahta kaşıklar bulunurdu. Bunlar muhtemelen seramonik malzemelerin yanı sıra asıl yemeklerde kullanılması içindir (İbn Battûta, 2000, s. I/495, 522).

Hükümdarlara özel yemek törenleri ile ilgili olarak Broquière ; Edirne'de iken Osmanlı Padişahı II. Murad'ın sarayını ziyaret edip buradaki törenlere katıldığındaki izlenimleri anlatırken değinir. Özellikle Osmanlı teşrifat kurallarına dair ipuçlarını bulabildiğimiz bu bölümde, bürokrasideki yemek kültürünü de anlayabilmekteyiz. II. Murad gelmeden önce orta yere yüz tane büyük kalaylı tepsi ve bunlardan her birinin üstüne de bir parça koyun eti konmuştur. Padişah oturur oturmaz yemek faslı başlar. Önce 
önüne ipek bir örtü serilir ve bir peşkir bırakılır; hünkâr bunu önüne çektikten sonra bakırdan mamul yuvarlak ve incelikle işlenmiş parlak kırmızı renkte bir sini koyulur. Adetlere göre bu sini sofra örtüsü yerine kullanilıyordu ve yemekler ancak böyle bir sini üstünde yeniyordu. Törenlerde altın tabaklardan yemek sunulduğunu II. Murad'a iki altın sahan içerisinde et yemeklerinin getirildiğini söylemesinden anladığımız Broquière, hizmetçilerin daha sonra sırasıyla yemekleri getirdiğini ifade eder. Fakat bu yemeklerden hünkâr yememiştir. Zira hünkâr ancak kendi özel sofrasında yiyip içer, onun ne yediğini, ne içtiğini pek az kişi bilir ve bundan da hiç söz edilmezmiş. Hünkâra sunulan bu yemek töreni esnasında sofrada ne ekmek ne de içecek bir şey vardır. Misafirlerden bazıları yemek yerken diğerleri daha yemeğini yemeye fırsat bulamadan sofra hizmetlileri kalan yemekleri toplanmaya başlamışlardır ve bu iş çok hızlıca halledilmiştir. Seyyah, yemek başlayıncaya kadar müzikli bir eğlencenin olduğunu ve bu eğlencenin padişah çıkıncaya kadar sürdüğünü söyler (Broquière, 2000, s. 245-247).

\section{Misafire Hürmet}

Yaşamış oldukları coğrafyalar fark etmeksizin Türk toplumlarının en önemli karakteristik özelliklerinden biri, misafirperver olmaları ve misafire değer vermeleridir. $\mathrm{Bu}$ nedenle Türk töresinde ve geleneğinde misafire hürmet, onu iyi karşılamak ve ağırlamak, misafire güler yüz göstermek ve onu memnun etmek, özellikle karnını doyurarak rahat ettirmek her Türk insanı için önemli ve zorunlu bir görev kabul edilir. Anadolu'ya gelmiş olan tüm seyyahların ortak söylemlerinden birisi de bu olmuştur. Zira hangi din ve rrktan olursa olsun misafir, misafirdir. Ayrıca İslam dininin ve Peygamberinin de bu konuyu teşvik eden birçok hadisi olması Türklerdeki bu hassasiyeti artırmıştır.

İbn Battûta, İbn Bibi'nin eserinde de "Lâdik" olarak anılan (İbn Bibî, 1996, s. 101) Denizli'nin Lâdik ilçesine vardığında Türklerdeki misafire verdikleri değeri göstermesi açısından önemli bir olay yaşar. Buna göre İbn Battûta şehre girip çarşıdan geçerken dükkânlardan çıkan bir takım kişiler, hayvanlarını çevirerek dizginlerine sarılır. Bu esnada başka bir grup daha gelerek onları durdurur ve kendi aralarında çekişmeye başlarlar. Aralarındaki münakaşa uzayınca bazıları hançerlerini çekip ötekilere saldırmaya bile kalkışır. Dillerini bilmeyen İbn Battûta ve yanındakiler gelenlerin Germiyanoğullarına ait eşkıyalar zanneder. Bu esnada Arapça bilen birisinin yanlarına gelerek durumu izah etmesiyle durum açığa kavuşur. Gelenler şehrin farklı ahi gruplarıdır ve münakaşanın sebebi her iki tarafında misafirleri kendi yanlarında konuk etmek istemeleridir. Münakaşa kura çekilmesi ile tatlıya bağlanır. Duruma ve misafirperverliğe çok şaşıran İbn Battûta bunu itiraf etmekten kendisini alamaz. Kurayı kazanan Ahi Sinan'ın adamları onları yanına alarak tekkelerine götürür ve hemen yemek ikram ederler. Yemeğin ardından dinlenmeye çekilirler ve biraz istirahat ettikten sonra hamama götürülürler. Hamamın çıkışında ise çeşitli meyve ve tatlılar ikram edilir. Sonra Kur'an dinlenir ve ahiler semaya başlarlar. Ertesi gün diğer ahi grubu misafirleri alır ve aynı şeyleri onlar da yaparlar (İbn Battûta, 2000, s. I/409-410).

Sadece konuk oldukları yerlerdeki önemli kişiler değil halktan zevat da bu ikram hususunda gayet isteklidir. Yukarıdaki örnekte de olduğu gibi halk da yabancı gördüklerini mutlaka misafir etmek, hiç bir şey yapamıyorsa en azından bir meyve ikramı ile ona hürmette bulunmak istemiştir. Nitekim buna işaret eden İbn Battûta, gezdiği birçok Türk yurdunda kendisine mutlaka meyve ve yiyecekler ikram edildiğini belirtir.

İbn Battûta ve yanındakiler, Sinop/Sanûb dolaylarında iken namazlarını Malikî mezhebine göre ellerini yanlara salarak kılar. Fakat yöre halkı bu mezhep hakkında bilgi SEFAD, 2019; (41): 427-444 
sahibi olmadıkları için, onları Şiilikle itham ederler. Onlar her ne kadar kendilerini anlatmaya çalışmışlarsa da Şii olmadıklarına inandıramamışlardır. Oranın beyi, İbn Battûta ve yanındakileri imtihana tabi tutmak için onlara bir tavşan gönderir. Çünkü İmâmiye Şiası'nda tavşan etinin haram olmasından dolayı onlardan bu âdeti alan Alevi gruplar tavşan yemekten imtina ederler (Ergun, 2011, s. 281-312). İbn Battûta ise durumu fark ederek tavşanı keser ve elleri ile pişirir, kendi tabiri ile afiyetle yer. Olaya şahit olanlar artık onlara inanırlar ve bundan sonra şereflerine ziyafetler verirler ve törenler yaparlar (İbn Battûta, 2000, s. I/444).

\title{
4. Yemek Çeşitleri
}

a. Süt ve süt ürünleri: Türklerin olmazsa olmaz yiyeceklerinin başında süt ürünleri, bunların arasında da tüm dünyaya yayılmış olan yoğurt gelir. Gittiği yerlerde de seyyahlarımıza hep süt, yoğurt, peynir gibi süt ürünlerinden ikram edilmiştir. Broquière, Anadolu'ya yönelik seyahatine başladığı arkadaşı ile birlikte sofraya oturduğu ilk akşam peynir ekmek yediğini, süt içtiklerini aktarmaktadır. Yine Karaman yurduna geldiği zaman kendisine sofra bezi üzerine sofranın kurulduğundan bahseder. Bu sofrada ekmek, peynir ve üzüm de vardır. Ardından seyyaha yoğurt ve yufka ekmek ikram edilir (Broquière, 2000, s. 154-155, 164,168, 170, 195-196, 265).

b. Ekmek: Broquière, Türklerin ekmeği yumuşak olarak tükettiklerini ve neredeyse bu ekmeklerin yarı pişmiş sayılabileceğini belirtir (Broquière, 2000, s. 174-175, 265).

Yukarıda belirttiğimiz üzere Broquière, Karaman'da iken ona yoğurt ve yufka ekmek ikram edilir. Bu yufka ekmeğin nasıl yenileceği de kendisine öğretilmiştir. Zira Broquière bu ekmeğin kıvrılarak nasıl yoğurta daldırıldığı ve içine yoğurtun alındığını tarif eder. Bu gün hâlâ Anadolu'nun bazı yerlerinde yapılan ve dıkım denilen ekmeğin kaşık gibi kullanılmasıdır. Broquière bahsettiğimiz yufkanın nasıl yapıldığına şahit olmuş ve bu durumu ayrıntıları ile anlatmıştır:

\begin{abstract}
"Ermeni o gün bizimle birlikte Türkmen çadırlarından birine geldi ve biz orada yine sütten yapılmış yiyecek yedik. Burada daha önce bahsetmiş olduğum ekmeğin nasıl yapıldığını gördüm: bu ekmeği o şekilde hazırlıyorlar ki ekmek sanki güneşte pişmiş gibi oluyor ama gerçekte güneşte pişirilmiyor. Bunları hazırlayan iki kadın gördüm ve nasıl yaptıkların seyrettim. Bu kadınlar yuvarlak biçimde, dümdüz bir hamur tahtası üzerine, pasta yapacaklarmış gibi bir miktar un koyuyor ve su katarak yoğuruyorlar; oluşan karışımı eze eze, oldukça yumuşak ve tam ekmek yapılacak kıvamda bir hamur haline getiriyorlar; sonra da bunu küçük küçük yuvarlak parçalara ayırıp bir oklava ile bu hamur parçalarından incecik yufkalar açıyorlardı ve bunu da şöyle yapıyorlardı: hamur parçasını oklavaya sararak tahta üzerinde yuvarlyorlar ve çok ince bir hale gelinceye kadar bunu sürdürüyorlardı. Bu işte çok usta ve hızlıydılar; bizde buna benzer pasta işi yapanlardan daha eli çabuk kimselerdi. Sonra dışa doğru hafif tümsek yapan bir sac levha getirdiler ve bunu bir sacayağı üzerine oturttular, altında da hafif bir ateş yaktılar; yufkaları sac levhanın üstüne yaydilar, alt üst ettiler; bunların pişmesi, bizim hamursuzun pişmesinden daha az sürdü." (Broquière, 2000, s. 168-170).
\end{abstract}

İbn Battûta ve yanındakiler, Huvârezm "Harezm" Beyi Kutlû Dümûr'un memleketine geldiklerinde onlara külîca adını verdikleri yağla pişirilmiş ekmek, kek ve helva ikram edilmiştir. Külîca muhtemelen kurabiye demektir (İbn Battûta, 2000, s. I/498, 522). 
c. Burhani (Borani?): İbn Battûta yukarıda da belirtildiği üzere Üzbek Hanlığg'na seyahatini anlattığı bölümde Türklerin bazı vakitlerde Burhani denilen hamur işini yediklerini söyler. Bu yemek, küçük küçük kesilmiş hamur parçalarından yapılır. Bu parçalar, ortalarından birer delik açılarak tencereye oturtulur. Pişirildikten sonra üzerine yoğurt dökülüp içilir (İbn Battûta, 2000, s. I/466-467).

d. Çorba: İbn Battûta, Ramazan ayında Özbek Han'ın sarayında bulunduğu sırada erişte çorbasına benzer bir çorba yediğinden bahseder ve bunu "rişta" kelimesiyle ifade eder. Ayrıca onun şehriyeye benzediğini ve piştikten sonra sütle karıştıılarak bir çorba şeklinde hazırlandığını anlatır. Broquière ise Türklerin bir gün boyunca yemek üzere bir avuç unla çorbamsı bir yemek yaptıklarını belirtir (Broquière, 2000, s. 265).

e. Bal: İbn Battûta, yine Sibirya bölgesini anlatırken içtikleri meşrubatların büyük bir kısmın ballı şıralardan oluştuğunu söyler (İbn Battûta, 2000, s. I/483-485). Broquière ise, bunların dışında ayrıca süt, bal, peynir veya üzüm ya da bir takım bitkiler yerdiklerini belirtir (Broquière, 2000, s. 265).

f. Ceviz sucuğu: Broquière, Karassar (Karahisar) da ceviz sucuğu yapımını da görür ve bunu şöyle anlatır: "Yöreye özgü bir yiyecek çeşidi daha gördüm: kabukları çıkarılmış taze cevizler ikiye bölünerek ipliklere dizilmiş bir halde, kaynamakta olan pekmeze daldırllıyor, çıkarllınca da tutkal gibi donuyordu. Bu yiyecek acıkıldığı zaman çiğ et ve diğerleri gibi insanın açlı̆̆ın bastırmaya yarayan iyi bir besindi." (Broquière, 2000, s. 195-196).

d. Serid: İbn Battûta, Eğridir'e geldiğinde Dündar Bek oğlu Ebu İshak Bek tarafından ona ikram edilmiştir. Bu muhtemelen tirit olarak bilinen yemek olmalıdır. Serid sofrada, ilk servis edilen yemektir. Seyyah, buradaki Türklerin "uğurlu olur" diyerek oruçlarını tiritle açtı̆̆ını belirtir. Bu iftarlığı, Hz. Muhammed (sav)'in diğer yemeklere tercih ettiğini ve kendilerinin "Biz onun güzel âdetine uyarak yemeğe seridle başliyoruz!" diyerek Hz. Peygamber'in (sav) sünnetine uymak için yemeğe seridle başladıklarını söylemişlerdir. Seridden sonra ise diğer yemeklere geçerler. Bu durum Ramazan ayı boyunca böyle devam eder (İbn Battûta, 2000, s. I/407). Burada bahsedilen yemeğin günümüzde tirit olarak bilinen yemek olduğunu düşünüyoruz. Hatta bu yemeği ilk olarak Hz. Peygamber'in dedesi Hâşim tarafından yapıldığı kaynaklarda geçmektedir. Hâşim, kıtlığın hüküm sürdüğü bir yıl Dımaşk'tan getirttiği ekmekleri et suyunda tirit yaparak hacılara ikram etmiş, bundan dolayı asıl adı Amr olmakla birlikte "Hâşim" (kıran, ufalayan, parçalara ayıran) lakabıyla meşhur olmuştur (İbn Sa'd, 1985, s. I/62-63; Belâzürî, 1990, s. I/67).

h. Et yemekleri: Broquière, Türklerin et kültürü ile ilgili olarak eti hiç pişirmeden veya kurutmadan çiğ olarak yemediklerini vurgular. Et, güneşte kurutulup çiğ olarak yenirdi. Eğer hayvanlardan biri ister at ister deve olsun, çaresini bilmedikleri bir ölüm tehlikesiyle karşılaşırsa onu vakit geçirmeden kestiklerini ve etini de işleyerek yediklerini ama tüm bu süreç içinde eti mutlaka az da olsa pişirdiklerini söyler (Broquière, 2000, s. 174175, 265). Ayrıca Bursa'ya geldiğinde Broquière 'ye akşam yemeğinde yarı pişmiş denilebilecek kıvamda ızgarada pişirilen et ikram edilir. $\mathrm{O}$, bu etlerin parça parça kesilerek ve bir şişe geçilerek ızgarada pişirildiğini aktarır. Ayrıca zeytinyağlı havyar yediğini belirttikten sonra eğer yanında başka yiyecekler yoksa Rumlar için bu havyarın hiçbir değerinin olmadığını söyler (Broquière, 2000, s. 199-204).

Broquière, Karassar'a (Karahisar) geldiğinde burada yemiş olduğu koyun ayaklarından yapılmış yemeği çok beğenmiştir. Muhtemelen günümüzde "paça" olarak 
anılan yemeğe karşılık gelen bu yemek için seyyah: "Şimdiye kadar yediğim yemeklerin en iyisi ve yediğim yemeklerin en güzeliydi." der. Konya ile Karahisar arasında pişmiş et yiyemediklerinden genelde kurutulmuş et yediklerinden şikâyet eden Broquiere, burada yolun devamı için yemek stoklar. Bol bol ekmek ve peynir alır (Broquière, 2000, s. 195-196).

İbn Battûta ise Sibirya bölgesindeki Türklerin yemeğinin haşlanmış at veya koyun eti olduğunu özellikle vurgular. Seyyah, et yemeklerini parçalamakla görevli kişilerden bahseder ve bunların nasıl çalıştıklarını anlatır: "Bârûcîlar eti küçük parçalara bölerler; kemikle karışık eti ayıklamada ustalık kazanmışlardır. Bârûcîlar kemikle yan yana pişmiş eti tercih ederler yemeklerinde." (İbn Battûta, 2000, s. I/483-485). Buradan sonra İstanbul'a geçen seyyah, yolculuk esnasında uğradıkları her konakta kafiledekilere dana eti, düki, kımız, inek ve koyun sütü gibi yiyecek ve içeceklerin ikram edildiğini yazar (İbn Battûta, 2000, s. I/483-485). Eski Türklerde at eti önemli bir besin kaynağı olup günümüze kadar tüketilmektedir (Solmaz, 2018, s. 101).

İbn Battûta, Huvârezm "Harezm" Beyi Kutlû Dümûr'un memleketine geldiklerinde ise emir kendilerine kızartılmış tavuk, turna, güvercin cücüğü, külîca (kurabiye) adını verdikleri yağla pişirilmiş ekmek, kek ve helva ikram edilir (İbn Battûta, 2000, s. I/498, 522).

\section{5. İçecekler}

a. Nebiz: Arapçadaki içkiyle alakalı kelimelerin bir kısmı ticari ilişkiler sonucu Farsça, Yunanca ve Süryanice'den alınmıştır. İçkiler yapıldıkları malzemeye göre halîtân, sahbâ, sekr, kındîd, nebîz, bit'u, cia, sükürke, mizr, fadîh gibi isimler almaktadır. Kuru üzüm, kuru hurma, arpa ve darı gibi maddelerden elde edilen bir içki türü olan nebizin helalliği konusu tartışmalıdır. (Bozkurt, 2000, s. 456.) İbn Battûta, Sibirya bölgesinde iken katıldığı bayram merasiminde helalliği tartışlan nebizin Hanefi mezhebine mensup olanlar tarafından helal sayıldığını ve yoğun olarak tüketildiğini aktarır. Yukarıda törenler bölümünde de belirtildiği üzere, nebiz içme belirli bir ritüele göre yapılır ve sultanın bizzat yakın ailesi törende hizmet ederdi. (İbn Battûta, 2000, s. I/483-485).

b. Boza: İbn Battûta, Kırım'da iken onu Tülük Tümûr davet eder. Bey, burada misafirine çeşit çeşit yemekler hazırlatmıştır. Yemek servisi yapılırken ilk olarak küçük kâselerde beyaz sıvı bir şey getirirler. İbn Battûta bunun ne olduğunu sorduğunda "dühn suyu" derler. Hiç bir şey anlamayan seyyah tadına bakınca ekşiliğinden rahatsız olur ve hemen bırakır. Yemekten sonra bu alışık olmadığı içeceği araştıran Battûta şöyle anlatır:
"Dûkî tanelerinden yapılan bir 'nebiz' dir bu. Onlar Hanefi mezhebindendir ve nebiz onlar nezdinde helaldir. Buralılar dîkîden yapılmış bu nebize buza adını veriyorlar. Şeyh Muzaferüddîn bana 'mâiddühn' [=dühn suyu] dediğinde dilinde biraz tutukluk ve yabancılık bulunduğu için 'yă̆ suyu' demek istediğini sanmıştım!" (İbn Battûta, 2000, s. I/469).

Bir kış içeceği olan ve yüksek kaloriye sahip, vücuda sıcaklık ve doygunluk hissi veren boza, Selçuklu Anadolusu'nda da sevilerek tüketilen mayhoş bir Türk içeceğidir. Yapılışı ise “Değirmende öğütülüp kepeği çıkarılan darı az miktar su ile koyuca pişirilip elekten geçiriliyor ve eski boza veya hamur mayası ile mayalandırılıp boza haline gelmek üzere serin yerde beklemeye alınıordu. İçine şeker atılıp ekşimesi sağlandıktan sonra da servis ediliyordu" (Turan, 2007, s. 21). 


\title{
c. Alkollü içecekler:
}

Broquière, Seyahatnâmede Türklerdeki içki içme alışkanlığı ile ilgili ayrıntılar verir. Seyahati esnasında birçok defalar gerçek kimliğini öğrenen Türkmenlerden bazılarının, ondan şarap tedarik etme cihetine gittiklerini belirtir. Özellikle bu dönemde bir Hristiyan'ın bir Müslüman'a şarap satması çok ciddi cezalar gerektiren suçtur. Bu yüzden han sahipleri Müslümanlara içki satamamaktadır. Bu durumu ise Müslümanlar, Hristiyanlara içki aldırmak yolu ile çözmeye çalışmaktadır. Konakladıkları bölgelerde Broquière 'nin de Hristiyan olduğunu öğrenen bazı Müslüman Türkler, ondan hancıdan şarap almasını istemişlerdi. Broquière yaşadığı bu tuhaf olayı şöyle anlatır:

\begin{abstract}
"Daha önce tanışmış olduğum Türklerden bazıları benim bir Frank'ın misafirhanesinde kaldığımı öğrenmişlerdi ve bir kenarda içmek için benden şarap almak amacıyla kaldı̆̆ıım yeri arayıp durmuşlardı; çünkü Mekke'den geldikleri ve kendi dinlerinde yasaklanmış olduğu için herkesin yanında şarap içemiyorlard. Bu konuyu Laurens'e açtım: o da bunu yapamayacă̆ını, zira bir Frenk'in bir Müslüman'a içmek için şarap verdiği öğrenilirse tutuklanacă̆ını ve bunun çok tehlikeli olduğunu söyledi. O zaman ben de bu cevabı kendilerine ilettim; onlar beni hiç beklemeden ayrlldılar ama şehirde bir Yunanlının otelinde şarap satıldığını zaten öğrenmişlerdi; onların içmek için şarap almaya mı geldiklerini, yoksa benimle birlikte eğlenmek mi istediklerini bilmiyordum. Beni ve beş Türkü yanlarına alarak o Yunanlının evine götürdüler; Yunanlı da bizi küçük bir mahzene indirdi, orada bir halka oluşturarak yere oturduk. Sonra Yunanl bize öyle bir toprak çanak getirdi ki içinde tam sekiz lot (yaklaşık 7.5 litre) şarap vardı; bunu altı kişiden oluşan halkanın orta yerine bıraktl, sonra gidip herkes için büyük birer şarap çanağı getirdi, sonra da iki derin tabak getirerek içine şarap koydu. Illk olarak sıranın başındaki başladı ve yanındaki arkadaşına kendi tarzlarına göre şarap içirdi ve sonra da sırayla diğerlerine verdi. Birbirimizin ardından gayet güzel içmeye başlamışı yemeden ara vermeden içiyorduk; bir an geldi ki çok içmekten elim ayağım tutmamaya başladı."
\end{abstract}

Hatta Broquière 'nin artık içki içemez hâle gelmesine sinirlenen bu kişiler, kendileri ile alay edildiğini zannederler. Durumu, yanında oturan ve Broquière 'ye "kardeş" diye hitap eden bir kişi, onun yerine de kendisinin içeceğini söyleyerek kurtarır. Broquière bunları anlatma nedenini de "Ben bütün bunları, içimizden biri günlerden bir gün onların topluluğuna katıldığı zaman, yerlere serilecek kadar içki içmek istemiyorsa bu adamlarla birlikte içmeye kalkışmasın diye anlatıyorum." diyerek izah eder ve kendisinin düştüğü hataya diğerlerinin düşmemesi için uyarıda bulunur (Broquière, 2000, s. 160-161). Yine seyyah, fazla içki içenlerin kendilerine gelmek için içtiklerini kustuklarını ve hemen ardından midesini içebildiği kadar su ile doldurduklarını ve böylece bir şişe suyla midesini yıkadıklarını yazar. Hemen hemen yarım gün boyunca midesini yıkayarak yol aldıklarını ve böylelikle iyileşip düzeldiğini belirtir (Broquière, 2000, s. 183).

\section{Meyveler}

Kaynaklardan tespit edildiği kadarıyla Selçuklu Anadolusu'nda alıç, armut, ayva, badem, ceviz, dut, elma, erik, fındık, fıstık, hurma, incir, kayısı, keçiboynuzu, kestane, nar, sumak, şeftali, portakal, limon ve üzüm gibi meyveler yetişmekteydi (Uzunağaç, 2014, s. 38). Buna temas eden el-Ömerî, Mesâliku'l-Ebsâr isimli eserinde coğrafi şartların ve iklimin elverişli olduğu Anadolu'da hemen hemen her türlü meyve yetiştiğini ifade etmektedir. (elÖmerî, 1991, s. 183). 
İbn Battûta'ya gezdiği birçok yerde kendisine mutlaka meyve ve yiyecekler ikram edilmiştir. Seyahatnâmede genelde kendisine meyve ikram edildiğini yazar fakat bunların hangi meyveler olduğunun ayrıntılarına pek girmez. Mutlak olan ise yol üzerindeki herkesin kendi imkânlarına göre yaptıkları ikramlardır.

Broquière de Bursa'daki izlenimlerini aktarırken bölge insanının koca yemiş dedikleri meyveleri tatmış ve "Irri kirazlardan daha büyük meyveler veren küçücük ağaçlar vardl; biçimi ve tadı çileği andırıyordu; ne var ki biraz ekşiydi, yemesi çok hoştu; ama çok yenince insan sarhoş gibi oluyordu; bu meyveler kasım ve aralık aylarında çıkarmış." sözleriyle bu meyveyi tarif etmiştir (Broquièr, 2000, s. I/199-204). 


\section{SONUC}

Milletlerin sahip oldukları zenginliklerinin tam olarak anlaşılabilmesi için kültürün önemli bir parçası olan yeme-içme alışkanlıklarının bilinmesi gerekmektedir. Toplumları en iyi analiz eden kaynaklar arasında Seyahatnâmeler önemli yer tutmaktadır. Seyyahlar, gezip gördükleri yerleri eserlerinde kaydederlerken olayları çoğunlukla kendi değer yargı ve kültürleri ile ilişkilendirerek aktardıkları için kıyas yapma imkânı sağlamaktadır. Nitekim İbn Battûta ve Bertrandon de la Broquière Seyahatnâmelerinde Türklerin yemek kültürlerine dair önemli bilgiler elde edilmiştir.

Türklerin eti genel olarak kurutarak yemekte, çoğunlukla süt ve süt ürünlerini tercih etmekte, ekmeği kurutmadan yumuşak olarak ve ince yufka şeklinde tüketmekte ve yemekleri ziyan etmemek için mutlaka sofra bezi tarzında bir şey kullanmaktadırlar. Türkler yemek yeme esnasında oradan geçen veya yemeğe rast gelen kişileri sofralarına davet etmekte, bunu bir şeref saymakta ve bundan dolayı herkes çekinmeden onların sofralarına oturmaktadır. Bir Avrupalı seyyah olan ve Türk geleneklerini de bilmeyen Broquière, Türklerin yaşamlarının çok zorlu olmasına ve fakir bir hayat sürmelerine rağmen sofralarına özellikle fakir insanları davet etmelerine şaşırmakta ve Avrupa'da böyle bir geleneğin olmadığını itiraf etmektedir. Özellikle şehir merkezlerinde beyler ve yetkili kişiler bu seyyahları misafir etmede özen göstermiş ve şereflerine birçok ziyafet tertip etmişlerdir. Hükümdarların ve beylerin ziyafetlerde kullandıkları yemek malzemelerinin imal edildikleri madenleri dikkati çekmektedir. Onların verdileri ziyafetlerde debdebeli altın yemek takımları kullanılmaktadır ki bu durum o hükümdarın veya beyin zenginliğini ve debdebesini göstermektedir.

Türkler meyve tüketimine önem vermekte ve yemeklerin ardından meyve yemektedirler. Ayrıca eğlencelerde ve törenlerde de yine meyveler sunulmaktadır. Bundan dolayı her çeşit meyvenin yetiştirildiği Anadolu'da seyyahların her gittikleri yerlerde kendilerine mutlaka meyve ikram edilmiştir.

İbn Battûta, Müslüman olması dolayısı ile şahit olduğu olayların ve ritüellerin arka planına ait çıkarımları daha net yapabilirken, Broquière, bunların bazılarını anlamlandırmakta zorlanmıştır. Fakat Broquière 'nin Hristiyan olması ise başta içki bulmakta zorlanan kişilerin onun vasıtası ile içki bulmaya yeltenmeleri gibi Müslüman olan kişilerin karşılaşmayacağı illegal yönleri aktarmasını da sağlamıştır. Yine Broquière 'nin kendi ülkesindeki yemek kültürü ile yapmış olduğu kıyaslamalar Avrupa ve Fransa mutfağı ve yemek kültürü hakkında bilgiler vermektedir.

\section{SUMMARY}

Food and drink are the most fundamental elements of human life. However, people simply don't eat and drink to survive. Food culture is a class indicator, a demonstration in relations between nations, an activity to be done in leisure time and an element of occasion for festivals. The historical development of societies can be monitored by following the food culture. Turks have a long history and a strong cultural background. An important part of this cultural accumulation they possess is the food and drink habits and the cultural elements shaped around it. The Turks moved these habits, which were shaped in the preIslamic Central Asian steppe life, to the territories where they migrated with migrations and continued their culture by influencing the societies in these new regions and by being influenced by them. In addition, they met with different beliefs and were subject to different 
religions, especially Islam. It is possible to see the traces of these habits today. Travellers can have more detailed information because they are not only concerned with not only the senior class but also sub-classes of the society and tell. In our study, we examined the food culture of Turks in the Middle Ages through the eyes of travellers traveling to the region where Turks lived. In order to capture different points of view, we preferred choosing travellers from different regions and religions such as Bertrandon de la Broquière and İbn Battûta. In this study, we have also tried to determine the culture of eating and drinking which has survived to the present day. We wanted to give more places for travel books in the study, but we limited it with travel books of the two travellers because it will exceed the size of an article.

In order to fully understand the riches of the nations, eating and drinking habits, which are an important part of culture, must be known. Among the sources that best analyse societies, itineraries occupy an important place. They provide the opportunity to make a comparison because they are mostly related to their own value judgments and cultures while recording the places travellers see and travel. Thus, important information about the food culture of Turks was obtained from the itineraries of Ibn Battuta and Bertrandon de la Broquière .

The Turks generally consume meat by drying it under the sun and by cooking it in certain regions in different ways. Grilling type cooking method is also frequently used among Turks. When their animals became severely ill, they would cut them and consume the flesh quickly. Turks, who frequently made a kind of food that is called brewis (Tirit) and a combination of extract of beef, meat and bread especially during Ramadan, generally consumed such local meat dish as trotter soup (Paca corbasi). In ceremonial dishes, ones, who were called baruci and whose tasks were to smash meat, served. In addition, roasted chicken, pike, pigeon meat, oil-baked bread called külîca (cookie), cake and halva were offered alongside of meat.

Dairy products are among the indispensable foods of Turks and yoghurt is spread all over the world. Our travellers were always served dairy products such as milk, yoghurt and cheese where they went.

The Turks consume bread softly and thinly in the form of dough without drying. They like the drink called Boza with a sourish taste as well as their traditional drink such as buttermilk. Particularly, this high-calorie drink gives them strength. There is also another kind of drink called Nebiz; it is a kind of drink that can make one drunk when it waits for a certain period of time just like Kımız or if it is over-consumed.

Turks used soup types frequently in their meals. Honey was consumed as a meal and was mixed with water to make slightly fermented grape juice. There were milk, cheese or grapes or a set of plants as well as honey. A kind of dessert, which is called churchkhela (ceviz sucuğu) and formed by the combination of walnuts, boiling of the molasses and turning them into the gel consistency, is a remarkable snack in the Western Anatolia for the Turks.

The Turks invites those who come to appear there during meals or run into the food at their tables and they count this as an honour and therefore everyone sits at their tables without hesitation. Broquière, who was a European traveller and didn't know Turkish traditions, was surprised by the fact that Turks invite people especially poor people to their 
tables in spite of their poverty and tough lives and he admitted that there is no such tradition in Europe.

Especially in the city centres, gentlemen and authorized persons took care of hosting these travellers and arranged many feasts for their honour. Pompous gold dinnerware was used in their feasts and this situation shows the wealth or state of that ruler or gentleman.

Turks pay attention to fruit consumption and eat fruit after meals. In addition, fruits are also offered in ceremonies and feasts. For this reason, fruit was absolutely served to travellers wherever they went in Anatolia where every kind of fruit is grown.

While Ibn Battûta was able to make clearer the implications of the background of the events and rituals he witnessed because of being a Muslim, Broquière had difficulty making sense of some of them. However, the fact that Broquière was a Christian made it possible to transmit illegal aspects that wouldn't be faced by Muslim people just like people having difficulty in finding a drink try to find a drink by means of it. Again, Broquière 's comparisons with the food culture of his own country provide information about European and French cuisine and food culture. 


\section{KAYNAKÇA}

Alptekin, A. B. (1992). Manas'in balalarıyla yedi gün. Millî Folklor, 16, $20-24$.

Aykut, A. Sait (1999). İbn Battûta. İslam Ansiklopedisi (Cilt 19, s. 361-368) içinde. İstanbul: Türkiye Diyanet Vakfı Yay.

Belâzürî, Ahmed b. Yahyâ b. Câbir (1996). Ensâbü'l-Eşrâf (Süheyl Zekkâr-Riyâd Ziriklî, Thk.). Beyrut: yy.

Bozkurt, N. (2000). İçki. İslam Ansiklopedisi (Cilt 21, s. 455-456) içinde. İstanbul: Türkiye Diyanet Vakfi Yay.

De La Broquière, B. (2000). Bertrandon de la Broquiere'in denizaşırı seyahati. (İ. Arda, Çev., S. Eyice, Der.). İstanbul: Eren Yayıncılık.

El-Ömerî, Şihâbüddîn Ahmed b. Yahyâ b. Fazlillâh (1991). Mesâliku'l-Ebsâr (Anadolu beylikleri hakkında araştırmalar I). (Y. Yücel, Çev.). Ankara: TTK Yayınları.

Ergun, P. (2011). Alevilik-Bektaşilikteki tavşan inancının mitolojik kökleri üzerine. Türk Kültürü ve Hacı Bektaş Velî Araştırma Dergisi, 60, 281-312.

Eyice, S. (1975). Bertrandon de la Broquière ve Seyahatnâmesi. İslam Tetkikleri Enstitüsü Dergisi, 6, 85-126.

Eyice, S. (1992). Bertrandon de la Broquière. İslam Ansiklopedisi (Cilt 5, s. 523-524) içinde. İstanbul: Türkiye Diyanet Vakfı Yay.

Hacıgökmen, M. A. (2013). Türklerde yas âdeti temelleri ve sonuçları. Tarihçiliğe adanmış bir ömür: Prof. Dr. Nejat Göyünç'e armağan (s. 393-423). Konya: S.Ü. Türkiyat Ens. Yayınları:

İbn Battûta, Ebu Abdullah Muhammed İbn Battûta Tancî (2000). İbn Battûta Seyahatnâmesi III. (A. S. Aykut, Çev.). İstanbul: Yapı Kredi Yayınları.

İbn Bibî, Nâsırüddîn Hüseyn b. Muhammed b. Alî el-Ca'ferî er-Rugadî el-Münşî (1996). elEvâmirüll-Alâ'iyye fi'l-Umûri'l-Alấ'iyye. (Mürsel Öztürk, Çev.). Ankara: Kültür Bakanlığı Yayınları.

İbn Haldûn, Ebu Zeyd Abdurrahman b. Muhammed b. Haldun el Hadramî (1956). Mukaddime. Beyrut: Dâru'l-Fikr.

İbn Sa'd, Ebû Abdillah Muhammed (1985). et-Tabakâtü'l-kübrâ. (İhsân Abbâs, Nşr.). Beyrut: Dâru Sadır.

Koçyiğit, T. (2009). İbn Battûta'nın Karadeniz seyahati üzerine bazı mülahazalar". Din Bilimleri Akademik Araştırma Dergisi, 9(4), 53-73.

Kofuoğlu, S. (1997). Hamîdoğulları. İslam Ansiklopedisi (Cilt 15, s. 471-476) içinde. İstanbul: Türkiye Diyanet Vakfı Yay.

Öcal, S. (1985). Eski Türklerde yiyecekler. Türk Dünyası Araştırmaları Vakfı Z. F. Fındıkoğlu Armă̆anı, 35, 161-213.

Ögel, B. (1978). Türk kültür tarihine giriş 4. Ankara: Kültür Bakanlığı Yayınları.

Öztürk, C. (2018). Türk tarihi ve kültürü. Ankara: Pegem Yay.

Rasonyi, L. (1971). Tarihte Türklük. Ankara: Türk Kültürü Araştırma Enstitüsü.

Solmaz, S. (2018). İbn Fazlan Seyahatnâmesine'ne göre İtil Bulgarları. Konya: Çizgi Kitabevi.

Sümer, F. (2001). Karamanoğulları. İslam Ansiklopedisi (Cilt 24, s. 454-460) içinde. İstanbul: Türkiye Diyanet Vakfı Yay.

Turan, A. N. (2007). Boza'yı kurcalamak. Acısıyla tatlısıyla boza. Ankara: Kültür ve Turizm Bakanlığı Yayınları.

Uzunağaç, Ö. (2014). Selçuklu Anadolu'sunda beslenme ve yemek kültürü (Yayımlanmamış yüksek lisans tezi). Marmara Üniversitesi, İstanbul.

Üstün, Ç. (2009). Eski bir Türk içeceği: Kımız (Koumıss). TÜBAR, 26, 247-255.

Yazıc1, H. (2009). Seyahatnâme. İslam Ansiklopedisi (Cilt 37, s. 9-11) içinde. İstanbul: Türkiye Diyanet Vakfı Yay. 